\title{
Nitinol one-way shape memory springs: Thermomechanical characterization and actuator design
}

\author{
G. Costanza*, M.E. Tata, C. Calisti \\ Mechanical Engineering Department, University of Rome “Tor Vergata”, Via del Politecnico 1, 00133 Rome, Italy
}

\section{A R T I C L E I N F O}

\section{Article history:}

Received 11 May 2009

Received in revised form

30 September 2009

Accepted 10 November 2009

Available online 13 November 2009

\section{Keywords:}

One-way shape memory effect

NiTi alloy

Heat treatments

High-cycle behavior

Linear actuator design

\begin{abstract}
A B S T R A C T
One-way shape memory effect (OWSME) in NiTi springs has been investigated in this work. The main goal is the definition of a guide-line for the design of a linear actuator for high cycles duty. Some SMA and steel springs with various geometrical features have been produced from wires with different diameters. SMA spring's behavior has been analyzed measuring the maximum length (austenitic condition, $T>A_{\mathrm{F}}-$ austenite finish) under different applied loads. The measurement of this length has been performed at successive thermomechanical complete working cycles $(150,5350,43,000$ and 600,000$)$ under a constant applied load necessary to full recovery in the martensitic phase. It has been found that the higher the thermomechanical cycles the lower the reached maximum length. In particular the length loss is negligible at higher cycles. Starting from these considerations and the knowledge of the mechanical characteristics of the springs, a linear actuator (SMA spring-harmonic steel spring) for high-cycle duty can be designed. The right working conditions have been verified too.
\end{abstract}

(C) 2009 Elsevier B.V. All rights reserved.

\section{Introduction}

Shape memory alloys (SMA), according to their property to recover a prefixed shape everytime heated above the transformation temperature, can be employed both as sensor and/or actuator. They can be used to supply a displacement or make a work: such a device can be defined "smart". Shape memory properties are due to the thermoelastic martensitic transformation which occurs during cooling. On the successive heating, martensite will be transformed into austenite, the only stable phase at this temperature. NiTi alloys can be easily deformed in the martensitic phase; however the previous shape can be achieved just heating above $A_{\mathrm{F}}$ temperature (Austenite finish). The shape memory effect has been found in many alloys [1-3]: CuAlNi, CuZnAl, AuCd, FeMn, but NiTi are the most common ones employed thanks to their features: corrosion resistance, ductility, high recoverable deformation, biocompatibility, etc. [4].

Shape memory actuators [5] show a high power/weight ratio, low cost and easy machining. Many techniques exist for the design of a two-way actuator: for example a localized treatment of the alloy can induce the shape memory effect only on a part of the material, so that the remaining part works as against-spring [6]. Another technique is to induce the two-way shape memory effect (TWSME) with a particular training procedure [7,8]. It has been found a fast

\footnotetext{
* Corresponding author. Tel.: +39 06 72597185; fax: +39 062021351.

E-mail address: costanza@ing.uniroma2.it (G. Costanza).
}

decline of the TWSME in NiTi springs [9] as the thermomechanical cycling proceeds. Besides, in literature many papers deal with the TWSME [10] but no one regarding the one-way shape memory effect (OWSME) on NiTi alloys in general and about springs in particular. Besides no correlation with high working cycles has been found. This aspect is very important in order to take into account the degradation of the shape memory property. In this work the effect of the working cycles has been investigated on the OWSME of NiTi springs. According to the experimental results of the thermomechanical cycles a simple guide-line for the design of a SMA linear actuator has been defined. A prototype of linear actuator with SMA spring and harmonic steel against-spring has been designed and built up in order to evaluate the feasibility of the project. In this actuator, as in the thermomechanical cycles, SMA spring is heated by Joule effect as a consequence of electric current flow through the wire. The aim of the harmonic steel spring is to push the SMA spring while cooling and to recover the starting condition in the martensitic phase for the successive activation.

\section{Experimental}

The investigation has been carried out on some commercial SMA wires provided by Memory Metalle with different diameters and compositions: two wires (diameters: 0.4 and $0.5 \mathrm{~mm}$ ) with a nominal composition of $\mathrm{Ti}-49.8$ at.\% $\mathrm{Ni}$ and transformation temperature $A_{\mathrm{F}}=65^{\circ} \mathrm{C}$ and a wire (diameter: $0.6 \mathrm{~mm}$ ) with a nominal composition of $\mathrm{Ti}-49.6$ at.\% $\mathrm{Ni}$ and transformation temperature $A_{\mathrm{F}}=95^{\circ} \mathrm{C}$ have been analyzed. Such transformation temperatures have been 


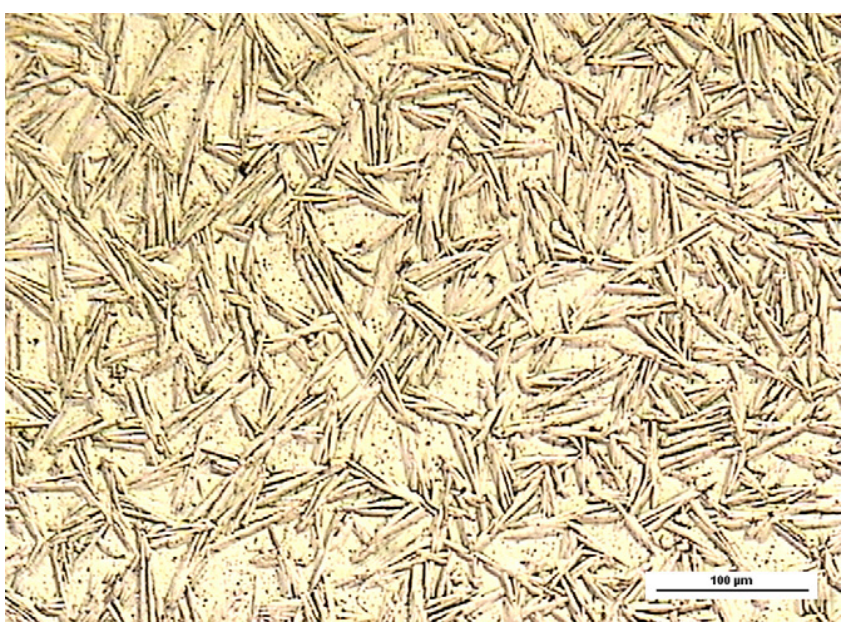

Fig. 1. The martensitic microstructure revealed after electrolytic polishing and chemical etching $(50 \times)$

confirmed by DSC measurements performed on SMA wires. The springs were prepared with a simple method: the NiTi wires were wound and locked on commercial screws with constant pitch; in this configuration they were annealed at $500^{\circ} \mathrm{C}$ for $15 \mathrm{~min}$ and water cooled [11] in order to impress the elongated shape to the SMA spring.

Metallographic examination was conducted after this treatment: electrolytic polishing $(90 \mathrm{ml}$ methylic alcohol, $10 \mathrm{ml}$ perchloric acid, cooled down with liquid nitrogen at $T=-20^{\circ} \mathrm{C}$, $\Delta V=12 \mathrm{~V}$ ) and chemical etching ( $30 \mathrm{ml}$ acetic acid, $5 \mathrm{ml}$ nitric acid and $2 \mathrm{ml}$ hydrofluoric acid) for $25 \mathrm{~s}$ evidenced the martensitic microstructure (see Fig. 1).

The springs with $0.4,0.5$ and $0.6 \mathrm{~mm}$ of wire diameter were identified as spring 1 , spring 2 and spring 3, respectively. The geometrical features of the springs are: mean diameter $3.5 \mathrm{~mm}$ for all springs, 14 active turns for spring 1,11 active turns for spring 2 and 12 active turns for spring 3 . Different active turns have been employed for springs 1 and 2 in order to obtain the same spring length in the martensitic phase $(6 \mathrm{~mm})$. For spring $3(0.6 \mathrm{~mm}$ wire diameter) greater active turns (12) and spring length $(7.8 \mathrm{~mm})$ were chosen because, due to the higher stiffness of the wire, to obtain $6 \mathrm{~mm}$ spring length it would be necessary a few turns (7). The first and the last turn of each spring were made transversally to the spring axis in order to obtain a simplified electric junction.

In Fig. 2 a sketch of the system used for thermomechanical characterization of SMA springs is reported. The SMA spring can move along the ceramic guide, passing from compressed shape (martensitic phase) to the elongated one (austenitic phase) when heated above $A_{\mathrm{F}}$ by Joule effect. The heating voltage applied on the extremities of the spring, selected on a suitable power supply, is in the range $2.5-3 \mathrm{~V} \mathrm{DC}$ for a few seconds (5-8 s). All the lengths reported in the present paper were measured by a simple caliper. Load cell was not necessary for force measurement because fixed weight were applied straight on each spring. The length in martensitic and austenitic phase are, respectively, the following: 6 and $27 \mathrm{~mm}$ for spring 1,6 and $32 \mathrm{~mm}$ for spring $2,7.8$ and $32 \mathrm{~mm}$ for spring 3. In order to reduce as more as possible the helical pitch and to eliminate the lowering of the spring under loads, the following procedure has been set up: springs were fully compressed in the martensitic state. Said $l_{M}$ the spring's length in the martensitic phase, it coincides with the difference between maximum length (in the austenitic phase) and displacement. In this way the characteristic curves load-displacement and load-maximum length show the same trend and are different for a simple translation.

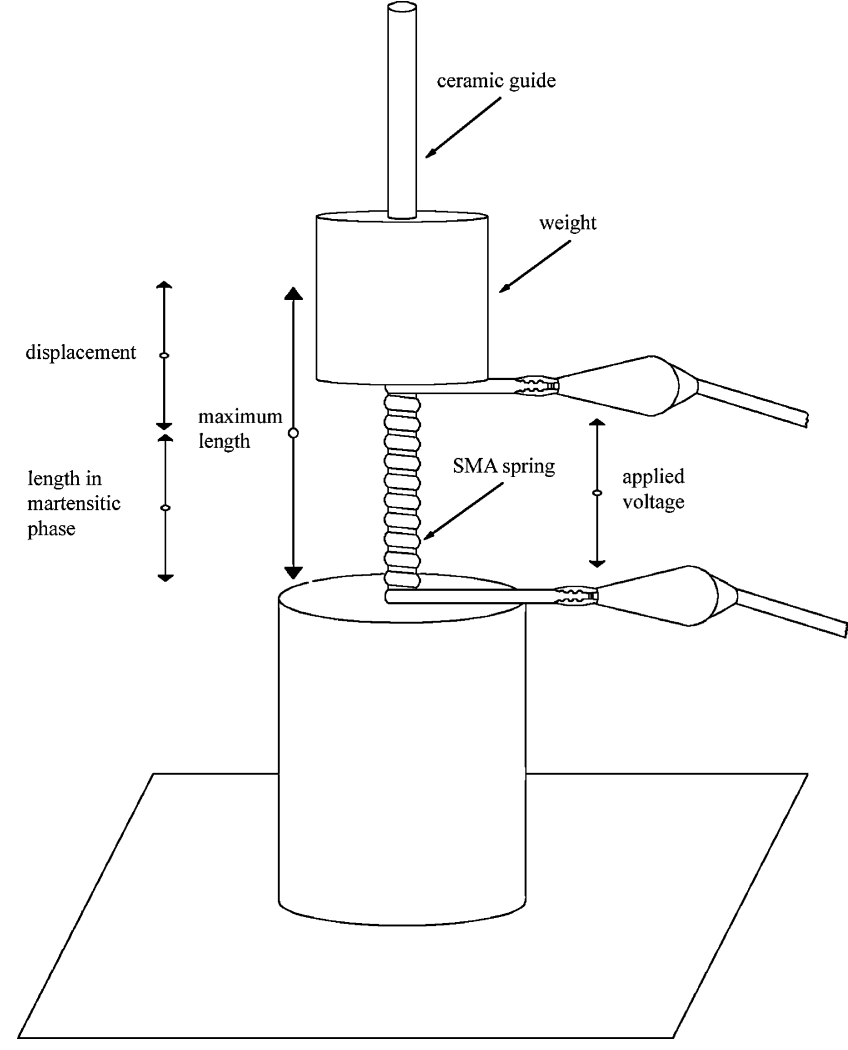

Fig. 2. A sketch of the device for the thermomechanical characterization.

For the thermomechanical characterization an experimental device has been designed and manufactured in order to subject SMA springs to many complete heating-natural cooling cycles in a fully automatic manner. It consists in a relay circuit actuated by a TTL signal coming from a function generator. In this way the whole cycle, $36 \mathrm{~s}$, was constituted by $6 \mathrm{~s}$ of activation (warming of the spring by Joule effect) and $30 \mathrm{~s}$ of open circuit (natural cooling phase). The applied voltage applied on the spring (2.5-3 V) was chosen to obtain complete austenite-martensite transformation cycle and vice versa. A metallic base with a ceramic guide fixed inside (see Fig. 2) has been adopted for the characterization and cyclic experiments of the springs. The selected weight for each test represents the spring force in correspondence of its maximum length.

Planning a SMA linear actuator, without resort to the TWSME, needs the presence of an against-spring by which the system can be automatically reset after each activation. For this reason six different harmonic steel springs have been fabricated in our laboratory starting from wires and winding on commercial screw. They have different active turns (11-17), wire diameter $(0.4-0.6 \mathrm{~mm})$ and mean turn diameter $(4.8-5.5 \mathrm{~mm})$ to cover a wide range of elastic constant: $101 \mathrm{~N} / \mathrm{m}$ (harmonic steel spring 1 ), $195 \mathrm{~N} / \mathrm{m}(2)$, $239 \mathrm{~N} / \mathrm{m}(3), 420 \mathrm{~N} / \mathrm{m}(4), 478 \mathrm{~N} / \mathrm{m}$ (5) and $500 \mathrm{~N} / \mathrm{m}(6)$.

\section{Results and discussion}

Experimental results of the SMA spring characterization in the austenitic condition (above $A_{\mathrm{F}}$ ) are reported in Fig. 3. In this figure the characteristic curves load-displacement of spring $1(0.4 \mathrm{~mm})$ and spring $2(0.5 \mathrm{~mm})$ are shown. As graphically evidenced, experimental data are well interpolated by polynomial curve of second degree. At higher applied load lower displacement occurs. The springs realize loads that decrease with the increase of displacement, in other words setting specimens heavier on the springs, their maximum lengths will be lower. The trend of the characteris- 


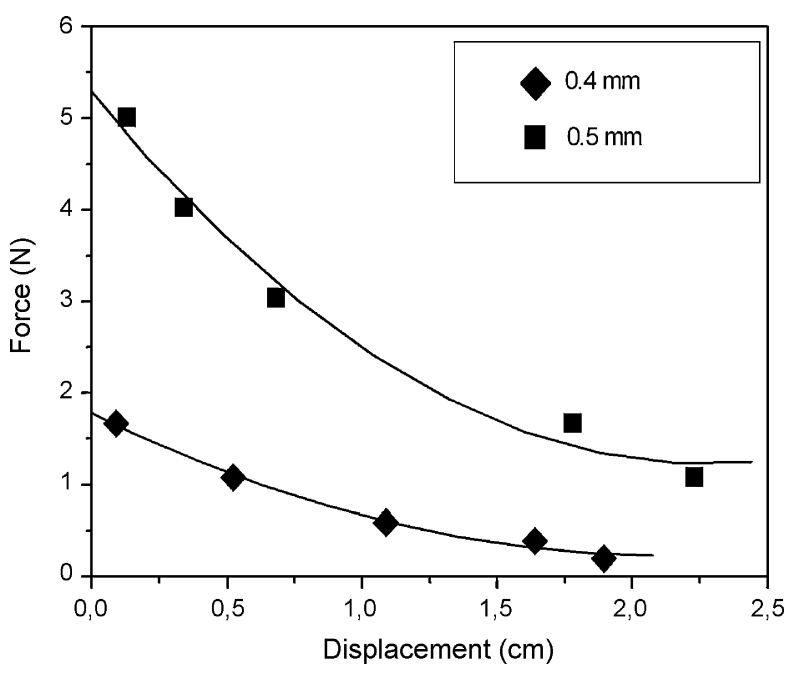

Fig. 3. Force/displacement characteristic curves for springs 1 and 2.

tic curves is monotonic decreasing and the spring 2 shows a higher slope. For example with a displacement of $1 \mathrm{~cm}$, the spring 1 offers a thrust of about $0.7 \mathrm{~N}$ while the spring 2 offers a thrust of about $2.5 \mathrm{~N}$.

Subsequently mechanical characterization of each spring has been performed at successive steps during thermomechanical cycles: as-manufactured, low ( 150 cycles, $1.5 \mathrm{~h})$, medium (5350 cycles, 2 days $)$, high ( 43,000 cycles, 15 days $)$ and very high $(600,000$ cycles, 232 days).

After the test of 150 thermomechanical cycles, carried out under different applied loads ( 20 and $40 \mathrm{~g}$, respectively, for the springs 1 and 2), SMA springs have been characterized again. Fig. 4 shows the force-displacement curves prior and after the 150 cycles test. As can be observed there is a degradation of spring's performance with a translation of the curves downwards, i.e. there are smaller maximum lengths under the same applied loads. The translation of the curve relative to spring 2 is higher than that of spring 1 ; the average loss on each cycle for the springs 1 and 2 are, respectively, $3 \times 10^{-4}$ and $6.7 \times 10^{-4} \mathrm{~cm} /$ cycle.

The springs underwent a further test of 5200 cycles under the same applied loads of the previous test; the curves plotted in Fig. 5 (maximum length vs. working cycles) show the degradation rate of one-way shape memory effect against the working cycles. In partic-

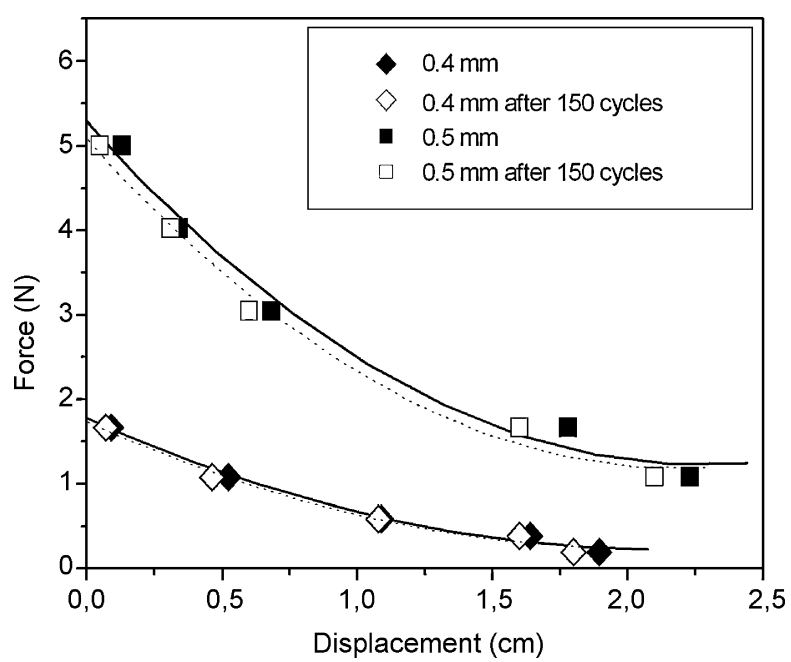

Fig. 4. Force/displacement characteristic curves for springs 1 and 2 after 0 and 150 cycles.

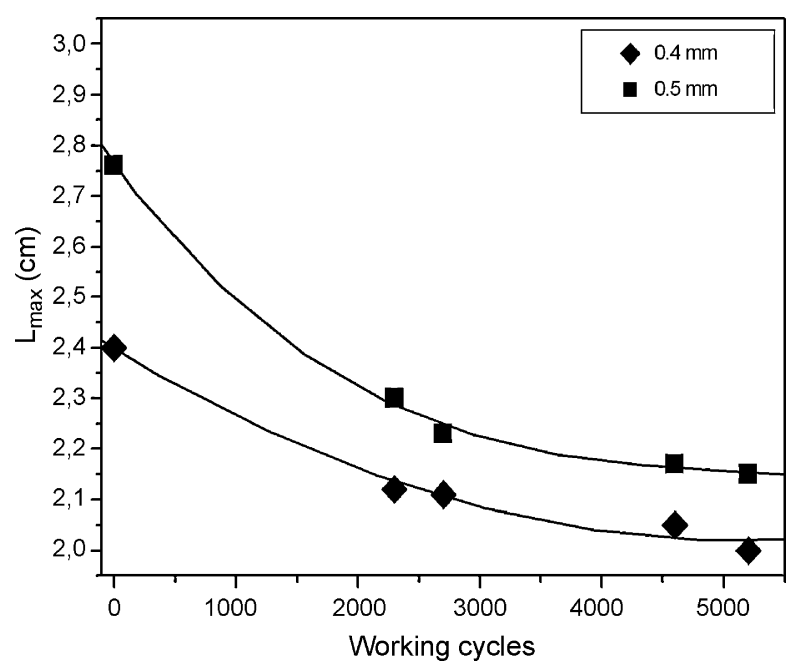

Fig. 5. Maximum length in the austenitic phase for springs 1 and 2 up to 5350 cycles.

ular there is a rather strong decay of maximum length in the early stage of working and the degradation rate decreases in the latter stage.

After 5200 working cycles test the new characteristic curves have been measured and reported in Fig. 6 in comparison with the curves of as-manufactured springs and after the 150 cycles test. There is a further translation of the curves downwards but there is a stabilization of the spring's behavior at higher cycles. In fact the average length loss for each cycle is lower; in particular the springs 1 and 2 have lost, respectively, $3.8 \times 10^{-5}$ and $8.3 \times 10^{-5} \mathrm{~cm}$ for each cycle.

To ensure the right working conditions of the actuator at high thermomechanical cycles other two tests have been carried out: 43,000 and 600,000 cycles for spring 1 . The spring one has performed 5350 cycles yet and it has been used again to carry out another 557,000 working cycles using an applied load of $20 \mathrm{~g}$.

The maximum length of the spring 1 is presented in Fig. 7 as a function of working cycles; this experiment has been started 2 days after the 5200 cycles test where, with $20 \mathrm{~g}$, the displacement of the spring has been of $1.4 \mathrm{~cm}$ and the maximum length has been of $2 \mathrm{~cm}$, as can be observed from Fig. 6 . In this new test with $20 \mathrm{~g}$, the initial maximum length has been of $2.2 \mathrm{~cm}$; therefore in the nooperation period there has been a little performance recovery. The

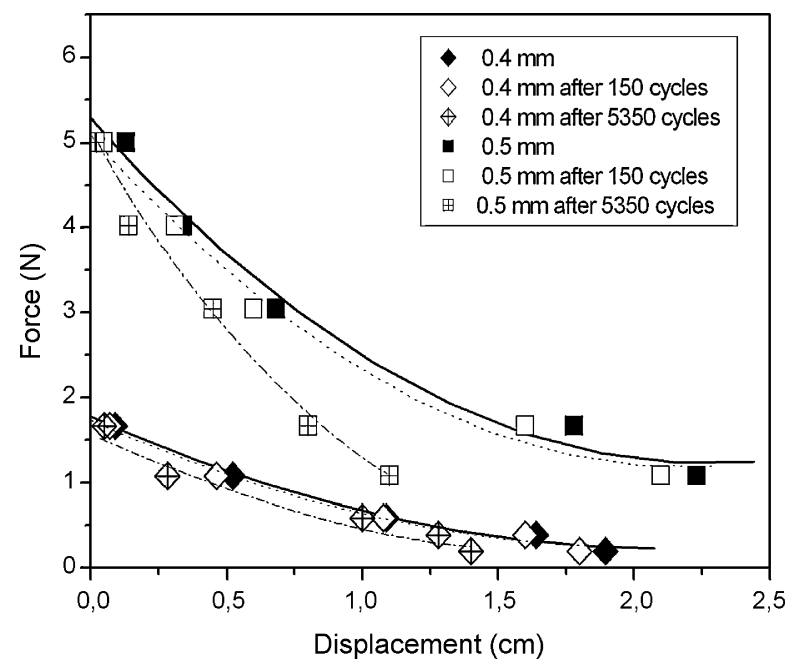

Fig. 6. Force/displacement characteristic curves for springs 1 and 2 after 0,150 and 5350 cycles. 


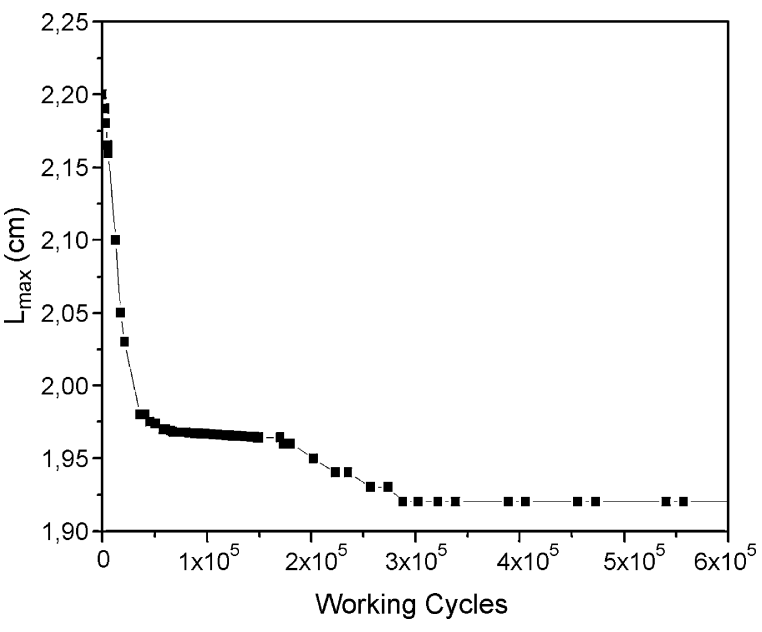

Fig. 7. Maximum length in the austenitic phase for spring one as a function of the thermomechanical working cycles.

curve plotted in Fig. 7 shows the degradation of one-way shape memory recovery rate; up to 40,000 cycles a quick degradation of maximum length occurs while at higher cycles the degradation is negligible. Again a stabilization of spring's behavior has been noticed at higher thermomechanical cycles.

Afterwards a test of 43,000 working cycles has been carried out using a mass of $40 \mathrm{~g}$ for the spring 3 (wire diameter $=0.6 \mathrm{~mm}$, $A_{\mathrm{F}}=95^{\circ} \mathrm{C}$ ); Fig. 8 shows the curve maximum length-working cycles of spring three. The degradation of the one-way memory effect shows the same features of the previous case; as can be observed in Fig. 8 there is a strong decay during the first thermomechanical driving cycles, in the latter stage the degradation rate is fairly low.

\section{Actuator design}

The scheme of the proposed linear actuator with a SMA spring and harmonic steel against-spring is illustrated in Fig. 9. The main purpose is the realization of a compact actuator in which the stroke of the active element (SMA spring) coincides with the actuator stroke. In the solution proposed by the authors both SMA spring and steel spring have been assembled discharged, without pre-stress. Fig. 10 shows both the characteristic curves of the SMA springs 1 and 2 (after 5350 cycles) and the six harmonic steel springs that have been fabricated. The characteristic curves of SMA springs and

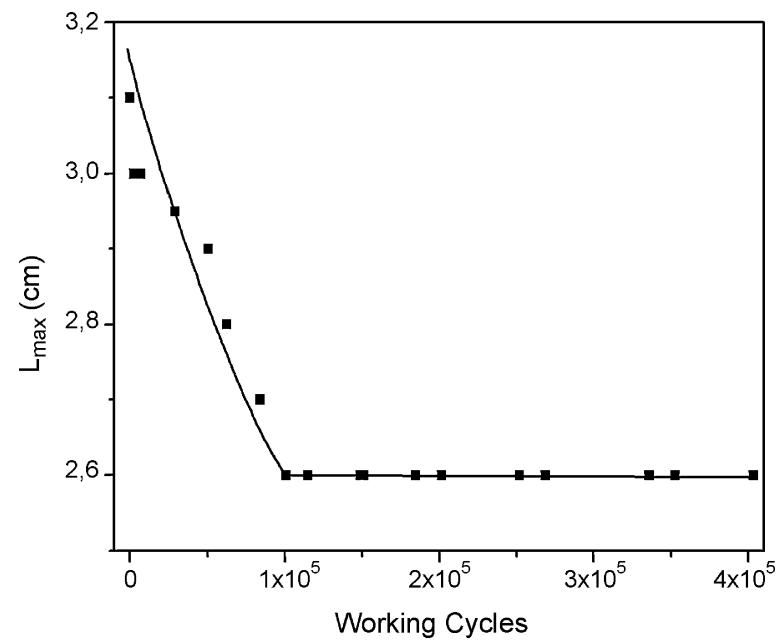

Fig. 8. Maximum length in the austenitic phase for spring three as a function of the thermomechanical working cycles.

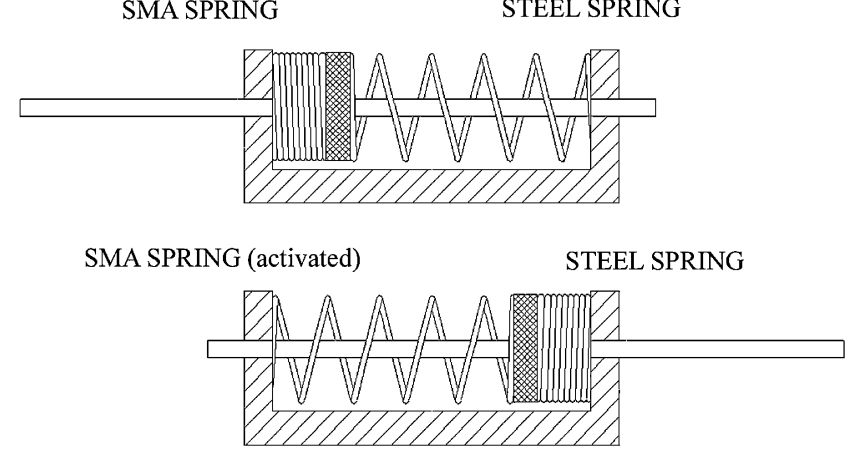

Fig. 9. A sketch of the designed and fabricated linear actuator SMA-steel spring.

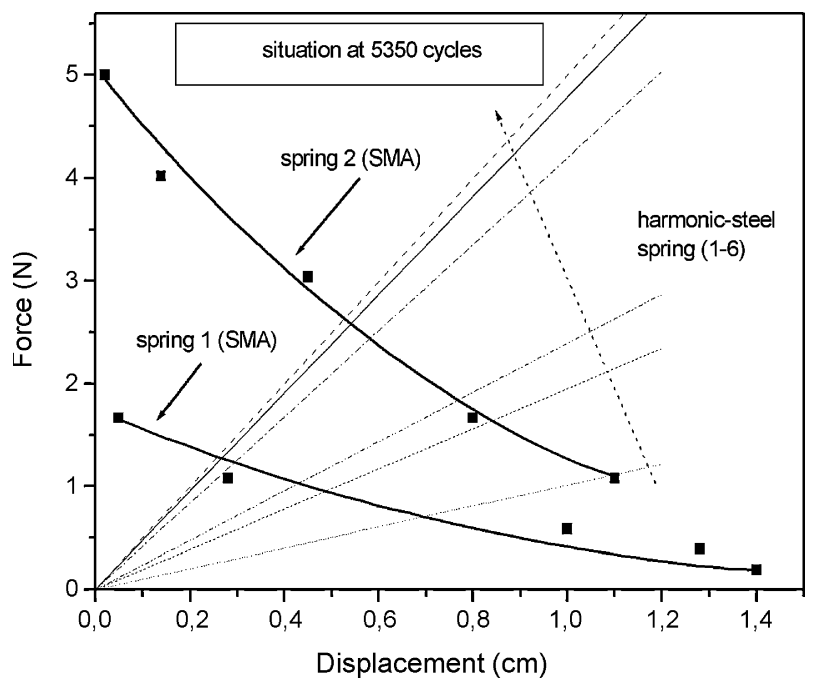

Fig. 10. A simple guide-line for the design of a linear actuator: the displacement in correspondence to the intersection of the curve is the actuator run.

steel springs have opposite slope because when a spring becomes longer the opponent spring shortens. Extremely important are the intersection points between the thermoelastic curve of the SMA spring and the elastic curve of harmonic steel spring. They identify the force and displacement in the equilibrium condition and consequently the actuator stroke. As shown in Fig. 10, it is possible to obtain a wide range of strokes just coupling different SMA spring and harmonic steel spring. For example the stroke ranges from 0.26 to $0.72 \mathrm{~cm}$ with the SMA spring 1 (wire diameter $=0.4 \mathrm{~mm}$ ) and from 0.52 to $1.08 \mathrm{~cm}$ with the SMA spring 2 . The strokes measured during actuator's working are in good agreement with the values obtained from the theoretical calculus of the elastic constants of each springs.

As it has been described above, the run of characteristic curves of SMA springs depends on working cycles; so Fig. 10 photographs the behavior of the springs at 5350 cycles. It is evident that the higher the number of cycles performed by SMA springs the bigger the insensitive of the spring's behavior to the working cycles.

\section{Conclusions}

Shape memory springs can successfully be employed to provide linear displacement. In this work some SMA springs have been fabricated and various thermomechanical tests (up to 600,000 complete heating-cooling cycles) have been carried out. It has been revealed that, in the heating phase, the thrust is in inverse relation to the spring's elongation. As can be observed from the experimental results of thermomechanical tests (force-displacement curves) 
there is a degradation of spring's performance with a translation of the curves downwards, i.e. there are smaller maximum lengths under the same applied loads. Some thermomechanical cycles test have been performed (150, 5350, 43,000 and 600,000 cycles) under different applied loads. It has been found that the higher the thermomechanical cycles the lower the maximum length but the length loss is lower at higher cycles. So there is a stabilization of the SMA spring's behavior with the increase of working cycles; this fact permits the realization of actuators in which stroke and force can be chosen from the designer and can operate for a high number of cycles. According to these considerations a linear actuator (SMA spring-harmonic steel spring) has been built up and the right working conditions have been verified.

\section{References}

[1] H. Funakubo, Shape Memory Alloys, Gordon and Breach Science Publishers, New York, 1987.

[2] J. Van Humbeeck, R. Stalmans, in: K. Otsuka, C.M. Wayman (Eds.), Shape Memory Materials, Cambridge University Press, Cambridge, 1998.

[3] W. Huang, On the selection of shape memory alloys for actuators, Materials and Design 23 (2002) 11-19.

[4] T. Duering, A. Pelton, D. Stöckel, An overview of nitinol medical applications, Materials Science and Engineering A 273-275 (1999) 149-160.

[5] S. Maeda, O. Tohyama, H. Ito, Micro actuators with shape memory alloy (SMA) coil springs and their application to active fiberscopes, IEICE Transactions on Electronics E-80C (1997) 226-231.

[6] Y. Bellouard, T. Lehnert, J.E. Bidaux, T. Sidler, R. Clavel, et al., Local annealing of complex mechanical devices: a new approach for developing monolithic micro-devices, Materials Science and Engineering A 273-275 (1999) 795-798.
[7] Z. Wang, X. Zu, X. Feng, J. Dai, Effect of thermomechanical treatment on the two-way shape memory effect of NiTi alloy spring, Materials Letters 54 (2002) 55-61.

[8] R. Lahoz, J.A. Puértolas, Training and two-way shape memory in NiTi alloys: influence on thermal parameters, Journal of Alloys and Compounds 381 (2004) $130-136$.

[9] Z.G. Wang, X.T. Zu, X.D. Feng, S. Zhu, J.W. Bao, L.M. Wang, Characteristics of two-way shape memory TiNi springs driven by electrical current, Materials and Design 25 (2004) 699-703.

[10] X.M. Zhang, J. Fernandez, J.M. Guilemany, Role of external applied stress on the two-way shape memory effect, Materials Science and Engineering A 438-440 (2006) 431-435.

[11] H.C. Kim, Y.I. Yoo, J.J. Lee, Development of a NiTi actuator using a two-way shape memory effect induced by compressive loading cycles, Sensor and Actuators A: Physical 148 (2008) 437-442.

\section{Biographies}

Girolamo Costanza graduated in Mechanical Engineering at the University of Rome 'Tor Vergata' in 1997. Since 2000, he has been working as assistant professor in the Department of Mechanical Engineering of the University of Rome 'Tor Vergata' where he teaches 'Metallurgy'. His fields of interest are MMC, coating, fatigue, shape memory alloys and metal foams. He is author of more than 50 papers.

Maria Elisa Tata graduated in Mechanical Engineering at the University of Rome 'Tor Vergata' in 1992. Since 2000, she works as assistant professor in the Department of Mechanical Engineering of the University of Rome 'Tor Vergata' where she teaches 'Metallurgy'. Her major research fields of interest are non-conventional materials, metal foams, shape memory alloys, Ti-based MMC and high strength steels. She is author of more than 80 papers.

Christian Calisti graduated in Mechanical Engineering at the University of Rome 'Tor Vergata' in 2008. He is now working at Corrocean, Ltd. 